\title{
A Behavioral Economic Study of Tax Rate Selection by the Median Voter: Can the Tax Rate Be Influenced by the Name of the Publicly Provided Private Good?
}

\author{
Neil J. Buckley1*, David Cameron², Katherine Cuff'3, Jeremiah Hurley², Stuart Mestelman33, \\ Stephanie Thomas ${ }^{4}$ \\ ${ }^{1}$ Department of Economics, York University, Toronto, ON, Canada \\ ${ }^{2}$ Department of Economics and Centre for Health Economics and Policy Analysis, McMaster University, Hamilton, ON, Canada \\ ${ }^{3}$ Department of Economics, McMaster University, Hamilton, ON, Canada \\ ${ }^{4}$ The School of Economics and Finance, Faculty of Business and Law, Curtin University, Perth, Western Australia \\ Email: ^nbuckley@yorku.ca, camerd@mcmaster.ca,cuffk@mcmaster.ca,hurley@mcmaster.ca, \\ mestelma@mcmaster.ca, Stephanie.Thomas1@curtin.edu.au
}

How to cite this paper: Buckley, N.J., Cameron, D., Cuff, K., Hurley, J., Mestelman, S. and Thomas, S. (2018) A Behavioral Economic Study of Tax Rate Selection by the Median Voter: Can the Tax Rate Be Influenced by the Name of the Publicly Provided Private Good? Theoretical Economics Letters, 8, 485-501. https://doi.org/10.4236/tel.2018.83034

Received: January 3, 2018

Accepted: February 11, 2018

Published: February 14, 2018

Copyright $\odot 2018$ by authors and Scientific Research Publishing Inc. This work is licensed under the Creative Commons Attribution International License (CC BY 4.0).

http://creativecommons.org/licenses/by/4.0/

\section{c. (i) Open Access}

\begin{abstract}
This paper presents the results of a behavioral economics study to test if the tax rates submitted to finance the public provision of a private good are influenced by changing the name of the private good. A revealed-preference laboratory decision-making experiment is used to test if participants choose significantly different tax rates to support provision of a private good named as a health care investment compared to an identical good named as a neutral monetary investment. Although some previous studies focusing on both framing and context effects find differences associated with health versus non-health environments, these studies have not involved voting over public provision of a private good. In our experimental environment, participants with different income endowments provide their preferred proportional tax rates for financing public provision of a private good in either a neutral or a health context. The implemented tax rate is the median preferred tax rate, and once the budget is determined, each participant receives the same quantity of the publicly provided private good. In each context, the payoff functions are the same. The only difference between the contexts is the name attached to the publicly provided private good, regardless of the name attached to the publicly provided private good, consuming it imposes no externalities. This controls for the positive externality characteristics of many health care goods, but not for preferences evoked by the merit good character of health care which factor
\end{abstract}


into decisions about the public provision of health care. We find that the theoretical predictions of the median voter model are generally supported by the data. However, the conjecture that the implemented tax rate would be affected by context is not supported by the results.

\section{Keywords}

Public Provision, Health Care, Tax Financing, Voting, Context Effect

\section{Introduction}

Recent papers have created environments to study mixed systems of public and private financing of the public provision of private goods in controlled laboratory environments. The goods studied all have the characteristics of excludability and the absence of externalities associated with their consumption. These could be goods such as health care or education or services such as garbage collection. [1] develops a simple discrete version of a majority-rule voting model of tax-financed public provision of a private good. Their treatment, which only allows for public financing, is extended to allow individuals to top up publicly financed consumption with privately financed units of the good or to opt out of consuming the publicly financed good and purchase all of their consumption privately while continuing to participate in financing the public provision. [2] further extends this environment to allow some or all individuals to exit from publicly financing the private good entirely.

The publicly financed private good in [1] was presented in a neutral monetary investment context. The neutral context follows an established tradition in experimental economics. However, recently there have been arguments presented that suggest even neutral contexts focused on questions about the effectiveness of the incentives created in controlled laboratory environments may result in some loss of experimental control. [3] and [4] discuss the need to consider the framing context of an experiment before drawing general conclusions because without that context, the experimenter is unable to control for the contexts participants impose themselves. [5] discusses "when and why" the context of the controlled laboratory environment that may matter and describe three types of context: abstract, meaningful and evocative. If participants instinctively create their own context for the neutral investment environment in order to better understand the problems, and especially if different participants choose different contexts, it is possible that researchers may lose some control of their environments.

In an attempt to focus on the incentives provided by publicly provided private goods, such as health care, researchers may unknowingly bias their results by using a neutral context. Because of the different, non-neutral, beliefs that the participants have about the value of publicly providing this private good, behavior may be observed that is unpredicted and difficult to understand. This may 
be particularly relevant if participants consider the publicly financed private good to be health care because the characteristics of health care often lead people to treat it differently from everyday consumption goods. With the exception of cosmetic procedures, demand for health care is derived from the demand for health and not health care itself. Health care is not consumed primarily for its direct effect on utility, but for its indirect effect on one's health status, which is an essential prerequisite for most activities of daily life (see e.g., [6]). Hence, generally individuals consume health care only when ill or injured, and it is needed to improve one's health status. These characteristics of consumption could therefore influence decisions about health care spending differently than decisions about spending on otherwise identical non-health care goods.

The characteristics of health and health care, including the asymmetry of information about health care between health care providers and consumers of health care, underlie the fact that, unlike standard consumption goods, in nearly all developed countries of the world (including the US when tax expenditures are included) the majority of health care is financed through the public sector. The goal is typically to ensure access to health care and its allocation according to need. Most societies treat health care as a merit good whose consumption should not be left entirely to an individual's ability and willingness to pay. If potential consumers of a publicly provided private good must vote on the value of the proportional income tax rate that will finance this provision, knowing specific details about the private good may be important. Individuals may have differing propensities to support public provision depending on whether they interpret the private good as say, health care, education or garbage collection. If alternative goods have identical characteristics, might the name the good is called have an effect on the decision that voters make?

[2] supplemented their neutral-context treatments of exit from a system of publicly financed private goods with health-context treatments. However, the health-context treatments that were presented were focused on investigating exit behavior from public finance and sample sizes were small. It is difficult to know whether the health-context effects found in the study would translate to a mandatory public financing environment if a larger data sample was collected. Using the three categories of context discussed by [5], the neutral context and healthcare contexts investigated by [2] may be identified as "meaningful". However, the health care context also has an "evocative" quality to the extent that it motivates feeling with respect to the merit good character of health care that cannot easily be induced in the laboratory environment.

This paper presents newly collected data expanding on the framework presented in [1] and [2] for which publicly financed private good provision is mandatory and is funded by a proportional tax on the income of the people who will receive the publicly provided private good. The instructions for the laboratory environments are presented in two different contexts. One context identifies the private good as health care and the other identifies the private good simply as a 
private investment good. The top-up, opt-out and exit options that were presented in [1] and [2] are not examined here; the focus is on systems of mandatory public finance.

The value of searching for context effects in an environment involving mandatory public finance is predicated on the observation noted above that nearly all countries in the developed world have some form of public health care and this suggests that people consider health care to be a merit good. Accordingly, creating a health context by simply using the words "health care" to describe the private good that is publicly provided may induce behavior that differs from behavior in a context which provides no indication of the nature of the private investment good other than the characteristics that are included as part of the instructions for the participants in a laboratory session which is identical for the two contexts. This is, therefore, a preliminary investigation of the minimum amount of context required to induce a behavioral response.

In this paper we present data from 40 groups of five participants who are each asked to provide the proportional tax rate on income that they would prefer to see imposed on all individuals in their group in order to provide resources to finance the supply of an equal amount of a private good to all members of their group. For 20 of the 40 groups the private good is presented as the result of an investment of resources into a group fund to finance, for each individual in the group, the opportunity to consume an equal amount of a private good that in turn will provide an equal return to each individual in the group. ${ }^{1}$ For an additional 20 groups of five participants the publicly financed private good is presented in the same way but the private good that is available for consumption is labelled as a health care good. ${ }^{2}$

To test for a context effect we focus on the implemented median tax rates in our two treatments. We also report the total public supply of the private good and the system returns across the two contexts (the former is directly related to the implemented tax rate and the latter is a crude measure of social welfare). None of the analysis presented in this paper has been reported elsewhere. We ${ }^{1}$ The data for 10 groups in the environment using the private-good-only context were run to study the effect of top-up and opt-out treatments relative to public-only provision (see [1]). The data used are from the groups in which the public-only treatment was run before the top-up or opt-out treatments. The data for another 10 groups in the environment using the private-good-only context were run to study the effect of universal-exit and exit-with-a-floor treatments relative to public-only provision (see [2]). The data used are from the groups in which the public-only treatment was run before the universal-exit or exit-with-a-floor treatments.

${ }^{2}$ The data for 10 of these "health" groups were collected for [2] to evaluate the exit treatments. The data used are from the groups in which the public-only treatment was run before the exit treatments. Data were collected from 10 additional "health" groups in May 2017 to increase the sample size to 20 groups. These data were collected for the purposes of the current study and are not presented elsewhere. This number of observations was selected to assure sufficient statistical power to identify a difference between the tax rates in the two contexts of at least 3 percentage points. This is described below in detail in subsection 4.2. The good identified as a health care good in this environment provides only private benefits. There are no positive or negative externalities associated with an individual's consumption of the health care good. However, identifying the private good as health care may evoke attitudes associated with the provision of merit goods when participants make decisions regarding the amount of the good that they wish to have provided publicly. 
find no significant context effects.

\section{Theoretical Framework}

We implement a standard political economy model of the public provision of a private good in a laboratory setting by adopting a discrete income distribution and a specific utility function (see [1]). There are $N$ individuals who differ in their fixed income (or endowment of a numeraire consumption good) denoted by $y$. The median income in the population is $y^{m}$, which is less than the mean income, $y^{m}$. Individuals have preferences over consumption of the numeraire good, given by $\mathcal{c}$, and of the private good that is publicly provided uniformly to all individuals, given by $h$. Individual preferences are represented by the utility function

$$
U(c, h)=a c^{\eta}+b h^{\eta}
$$

where $a, b>0$ and $0<\eta<1$. The publicly financed private good is produced using the numeraire good. Following the literature, it takes one unit of the numeraire consumption good to produce one unit of the publicly provided private good.

The publicly provided private good is financed by a proportional income tax $t$ levied on all individuals' incomes. The government's budget constraint is

$$
t y^{m}=h
$$

and the individual's budget constraint is

$$
c=y-\left(y / y^{m}\right) h
$$

Let $T(y)=\left(y / y^{m}\right)$ be the individual's relative tax price for the publicly financed private good. Using the Equations (3) and (1) we can solve for the individual's induced utility function with respect to the public provision of the private good

$$
V(h) \equiv \max a(y-T(y) h)^{\eta}+b h^{\eta}
$$

where $h \geq 0 . V(h)$ is strictly concave in $h$. This results in a unique preferred tax rate and a unique amount of public provision of the private good for each individual given public financing through a common proportional income tax levied on each individual in the group. Both the preferred amount of $h$ and the preferred tax rate will be strictly decreasing in the individual's income. Under majority-rule voting, the preferred tax rate of the median income individual will be the implemented tax rate and this individual's preferred public provision of the private good will be supplied to each individual regardless of income. ${ }^{3}$ Therefore, we have the following theoretical predictions:

Theoretical Prediction 1: In a public-only financing system, preferred tax rates are strictly decreasing in income, and

Theoretical Prediction 2: In a public-only financing system, the preferred tax

${ }^{3}$ The formal statements of the predicted tax rate and public provision of the private good are presented in [1] and follow directly from applying the median voter theorem. 
rate of the median income individual will be implemented under majority-rule.

Because the implemented tax rate is the tax rate preferred by the median income individual who, by assumption has an income below the mean income level, public provision of a private good effectively redistributes income (and utility or payoffs) from the highest income individuals to the lowest income individuals.

\section{The Health Care Context}

The health context modifies only the language of the experimental instructions without changing the underlying decision problem and financial incentives faced by the participants. We are specifically interested in whether individuals make different decisions about their preferred tax rates to fund a publicly financed private good if

1) The good is described as an equal share from the resources deposited into a Group Investment Fund that is then invested in a private Market which yields a return that is equal for everyone in the group or;

2) The good is described as an equal share from the resources deposited into a Group Health Care Fund that is then deposited into a personal Health Care Account which yields a return that is equal for everyone in the group.

In the private-good (neutral) context participants are told that the total taxes collected $\left(5 t y^{m}\right)$ in the Group Investment Fund are divided equally amongst everyone, so each individual receives $h$, which is then invested in Market A. The payoff to each individual from Market $\mathrm{A}$ is equal to $b h^{\eta}>h$. The income not taken as a tax from each individual $(c)$ is put into a Private Investment Fund that invests in Market B on behalf of the individual and the proceeds result in the payoff to the individual equal to $a c^{n}>c$. $h$ is determined by (2) and $c$ is determined by (3).

In the health context, participants are told that the total taxes collected $\left(5 t y^{m}\right)$ in the Group Health Care Fund are divided equally amongst everyone, so each individual receives $h$, which is then placed into the individual's Health Care Account. The payoff to each individual from this Health Care Account (from the ability to consume up to $h$ units of health care) is equal to $b h^{\eta}>h$. The income not taken as a tax from each individual is put into a Private Fund that invests in a Private Investment Account on behalf of the individual and the proceeds result in the payoff to the individual equal to $a c^{\eta}>c . h$ is determined by (2) and $c$ is determined by (3).

As noted, one reason health care is said to be different from conventional consumer goods is that its demand is "derived" from the demand for health: people purchase health care not for its direct effect on utility, but to improve their health when they are ill or injured. We can consider the public provision of health care in our environment as the provision of public funding to enable participants to purchase needed health care. It provides each participant the ability to access $h$ units of health care during the period of time for which the payoff 
function (1) is relevant. For the participant, the ability to access these units during this specific period of time has the value $b h^{\eta}>h$. We can consider the neutral investment context in a similar way. Each participant has the ability to consume $h$ units of a private good produced in Market A with the resources in the investment fund during the period of time for which the payoff function (1) is relevant. The participant's ability to access these units has the value $b h^{\eta}>h$. If the health context evokes recognition that there is a merit component to the provision of the health good that does not exist for the neutral good, the resulting values of $t^{*}$ and of $h^{*}$ may be different in the different contexts.

This different terminology was introduced to provide participants with a decision between an explicitly named health care option and an explicitly named private investment option while ensuring an identical experimenter-induced outcome and payoff situation for the two contexts. If the only difference between the two contexts is the name used to describe the publicly provided private good, then according to the theoretical model there should be no difference in behavior. More poetically stated.

"What's in a name? That which we call a rose by any other name would smell as sweet:" [[7], p. 404, lines 43-44].

Considering alternative contexts for our laboratory environment leads to our research question.

Question: Is there a difference in the implemented tax rate to finance the public provision of a private good if the good is presented as a health care good rather than as a generic private good?

While our theoretical model does not predict any behavioral differences between alternative contexts for the tax rates that will be preferred by individuals, the question of whether a health care context effect might exist in our setting is an interesting one. If participants recognize that the private good identified as health care has comparable properties to the good identified as a conventional private good (no positive externalities from consumption or merit good properties), there should be no difference in the outcomes associated with each context. If some participants associate the health care good with a commonly held belief that it is a merit good, we would expect to find greater investment in health care goods through a higher preferred tax rate (to account for a positive return to the participant, above the induced return provided by the experimenter, for contributing to the financing of a merit good). The literature does not provide an unambiguous answer to our question.

[8] and [9] have previously investigated health versus neutral contexts of experiments, with a focus on the influence of professional norms on physician decision-making regarding the provision of services. They find positive effects of the health frame on services provided.

[10] studies an environment in which both public and private insurance is available to individuals in a laboratory environment. The private insurance guarantees that the insured receives compensation for a loss before anyone with 
public insurance receives compensation. The public insurance guarantees protection for the people with public insurance who have the greatest likelihood of a loss given that the resources to provide compensation are available. In one treatment compensation is characterized as being cash to purchase health care for an illness. In the second treatment compensation is characterized as being cash for a loss. They find that when compensation from public insurance is rationed by need, individuals' willingness-to-pay for private insurance is lower in the health care context than in the cash-for-a-loss context. However, when compensation from public insurance is rationed randomly (first-come, first served) there is no difference between willingness to pay for private insurance in the health care and generic loss contexts.

[2] found significant effects of context on exit behavior from public finance of a private good when a privately financed alternative was available. They found that a greater percentage of people exited from public provision with the health context than with the neutral context. These results were more consistent with the theoretical prediction on exit than were the neutral context results and not consistent with a belief that people would recognize the merit good character of health care and be less likely to exit from public provision than if the good was framed neutrally and did not evoke this merit good characteristic.

We do not have a theoretical model that can offer a prediction for a context effect in this environment. Neither do we have consistent behavioral evidence from other experiments to suggest a context effect for the tax rate that will be implemented for this environment of the public provision of a private good. The data from this experiment will help to identify a context effect.

\section{Parameterization and Laboratory Implementation}

\subsection{Parameterization}

The payoffs to individuals were calculated using the payoff function given by Equation (1), where the return to the individual's share of the Group Investment Fund (the Group Health Care Fund in the health context) is $b h^{\eta}$ and the return to the individual's investment in Market B (the Private Investment Account) is $\mathrm{ac}^{\mathrm{l}}$. The parameter values and the incomes of the five participants in each group who shared the publicly provided private goods were those used in [1] and [2] and were chosen to assure the saliency of participant decisions in the experiment. The parameter values for (1) are: $a=20, b=22$ and $\eta=0.6$. The incomes are $\mathrm{L} \$ 125, \mathrm{~L} \$ 275, \mathrm{~L} \$ 640, \mathrm{~L} \$ 700$ and $\mathrm{L} \$ 1500$.

Based on these parameters and incomes, the theoretically predicted implemented tax rate that would result from payoff maximizing decisions is $56.4 \%$. The predicted total consumption of the private good is 1827 units. The predicted total payoff received by the five members of each group that is associated with this tax rate is $L \$ 6550$.

\subsection{Laboratory Implementation}

Twenty computer-mediated laboratory sessions were run, each with ten partici- 
pants who were told that they would be randomly assigned to be a member of a group of five people, but were not told who was in their group. In total there are 20 groups of five participants who experienced the neutral context and 20 groups of five participants who experienced the health context for a total of 200 participants. ${ }^{4}$ The data analyzed here are summarized by source, treatment and context in Table 1.

Table 1. Data sources, treatments, session contexts and participants.

\begin{tabular}{|c|c|c|c|c|c|}
\hline & Source of data & $\begin{array}{l}\text { Treatment for } \\
\text { periods } 1-10\end{array}$ & $\begin{array}{l}\text { Treatment for } \\
\text { periods } 11-20\end{array}$ & $\begin{array}{l}\text { Session } \\
\text { context }\end{array}$ & $\begin{array}{c}\text { Number of } \\
\text { participants } \\
\text { (Groups) }\end{array}$ \\
\hline 1 & JEBO 2015 & Public only & Top up & Neutral & $25(5)$ \\
\hline 2 & JEBO 2015 & Top up & Public only & Neutral & $25(5)$ \\
\hline 3 & JEBO 2015 & Public only & Opt out & Neutral & $25(5)$ \\
\hline 4 & JEBO 2015 & Opt out & Public only & Neutral & $25(5)$ \\
\hline 5 & JEBO 2016 & Public only & Universal exit & Neutral & $25(5)$ \\
\hline 6 & JEBO 2016 & Universal exit & Public only & Neutral & $25(5)$ \\
\hline 7 & JEBO 2016 & Public only & Conditional exit & Neutral & $25(5)$ \\
\hline 8 & JEBO 2016 & Conditional exit & Public only & Neutral & $25(5)$ \\
\hline 9 & JEBO 2016 & Public only & Universal exit & Health & $25(5)$ \\
\hline 10 & JEBO 2016 & Universal exit & Public only & Health & $25(5)$ \\
\hline 11 & JEBO 2016 & Public only & Conditional exit & Health & $25(5)$ \\
\hline 12 & JEBO 2016 & Conditional exit & Public only & Health & $25(5)$ \\
\hline 13 & May 2017 & Public only & Universal exit & Health & $25(5)$ \\
\hline 14 & May 2017 & Public only & Universal exit & Health & $25(5)$ \\
\hline
\end{tabular}

Notes: The data analyzed are the data from rows $1,3,5,7,9,11,13$ and 14 (in bold font). This comprises data from 200 participants in 40 groups of 5 participants. 20 groups are run with the neutral context and 20 groups are run with the health context. The 40 groups are independent of one another. Data from "JEBO 2015" and "JEBO 2016" are from [1] and [2], respectively. The data from May 2017 were run to complete the experimental design and have not been published elsewhere.

Each group remained together throughout the session so that the two groups in each session represented independent observations. Participants were told, at

${ }^{4}$ Instructions used in the experiment can be found in [1] and [2]. As noted in footnotes 1 and 2, the data for the 20 groups with the neutral context and the data for the first 10 groups with the health context were collected and analyzed in [1] and [2]. This original sample size was inadequate for finding context effects in a public-only finance setting. Given the mean (and standard deviation) of the implemented tax rates in the neutral context of $55.24 \%$ (3.40\%), the statistical power of finding a 3 -percentage point difference in contexts in this case was only 0.63 based on a two sample t-test of differences at a 5\% significance level (see e.g. [11]). For the situation we are considering we do not believe that a difference of less than 3-percentage points is economically meaningful. To increase the statistical power of finding a context effect, should one exist, the sample size for the health context groups was increased by 10 additional groups in May 2017. With these additional groups there is now a statistical power of 0.80 of finding a 3-percentage point difference, signifying an $80 \%$ confidence that our testing correctly rejects a null hypothesis of no context effect when the alternative hypothesis of a context effect is true. The statistical power increases to 0.96 in finding a context effect difference of 4-percentage points between tax rates should there be one. All of the data that is analyzed here includes 10 new health context groups and is analyzed differently than how the original data were analyzed in [1] and [2]. 
the beginning of each decision period, that each member of their group would randomly be assigned an income, expressed in laboratory dollars (L\$), from the following set of five income levels (L\$125, L\$275, L\$640, L\$700, L\$1500), and that each participant would be assigned each of the income levels twice over the course of the ten periods of the treatment. The income distribution was chosen to ensure that the median income was below the mean (consistent with the theoretical assumption needed to assure the median voter's choice of public provision would be supported if there was a majority-rule vote on public-only versus private-only provision). ${ }^{5}$ To keep participants actively thinking about their decisions, incomes were assigned in a pre-determined pseudo-random order such that in each session participants experienced each of the five income levels in the first five periods and then again in the last five periods of the treatments in which they participated, but the income levels were experienced in a different order over each five period phase. Each of the five participants in a group was instructed to submit the tax rate that he or she prefers to have imposed on everyone in the group to finance the provision of the private good given that the median of the preferred tax rates would be selected and implemented. The implemented tax rate determines the group's contribution to public finance and the tax revenues are then divided equally amongst the 5 group members to provide consumption of the private good. The median voter is the voter whose submitted tax rate is the implemented tax rate.

The average participant payoff was $\$ 23$ including a $\$ 5$ show-up fee for a 20 -period session. Sessions lasted approximately 70 minutes. ${ }^{6}$ Participants were randomly recruited from the undergraduate student population at McMaster University. Participants were individually paid their cash earnings in private. The experiment was conducted using z-Tree software [12] and the McMaster University Research Ethics Board approved the laboratory protocol.

\section{Experimental Results}

The first theoretical prediction, that preferred tax rates will fall as endowment increases, is evaluated using a linear regression in which context, endowment and whether or not the observations are from the second 5-period phase of the treatment are included as dummy variables. There are 2000 observations in total collected from 20 independent groups of five participants in the health context (over ten periods) and 20 independent groups of five participants in the neutral context (over ten decision periods). There are 1000 observations for periods 1 - 5 and 1000 observations for periods 6 - 10. For the regression analysis data are clustered on group. Table 2 presents the mean actual values and predicted values of preferred tax rates by endowment, context and phase while Table 3

${ }^{5}$ This distribution of income is roughly representative of the incomes at the 10th, 30th, 50th, 70th and 90th percentiles in Canada in 2013.

${ }^{6}$ None of the participants had prior experience with this environment. Each 10-period portion of a session would have taken perhaps 25 minutes to complete. The average payoff is about $\$ 9$ for each 10 -period portion. 
presents the regression results.

The regression results indicate that the context effect on preferred tax rates is not statistically significant $(\mathrm{p}=0.110)$. There is a very small, but statistically significant, phase effect of about 1.37 percentage points $(\mathrm{p}=0.018)$. Preferred tax rates are slightly greater across the last five periods of the treatment than across the first five periods. Finally, as endowment increases the preferred tax rates fall (each pairwise change is significant at a $1 \%$ level of significance or lower). This supports Theoretical Prediction 1.

The second theoretical prediction, that the implemented tax rate will be the preferred rate of the individual with the median income (L\$640), is evaluated using a probit regression model that regresses a binary variable identifying whether an observation was from the individual whose submitted tax rate is the implemented tax rate (i.e. the median voter) on explanatory variables indicating context, endowment and whether the observations are from the second 5-period phase of the session or not. The regression data are clustered on group. There are 400 tax rates determined by participants in the environments studied here (200 in each of the health and neutral context treatments). In 48 of these periods the median tax rate was the preferred tax rate of two people who submitted identical rates. In one period, the median tax rate was the preferred tax rate of four people. Therefore, our analysis proceeds with 451 contributors to the 400

Table 2. Predicted tax rates (percentages) by endowment and mean actual tax rates (percentages) by context (health or neutral), endowment and phase (periods 1 - 5 or periods 6 $10)$.

\begin{tabular}{cccccc}
\hline & & \multicolumn{2}{c}{ Phase 1 (periods 1 - 5) } & \multicolumn{2}{c}{ Phase 2 (periods 6 - 10) } \\
\hline Endowments & Predicted & Neutral & Health & Neutral & Health \\
\hline 125 & 93.7 & 79.73 & 73.75 & 82.99 & 78.17 \\
275 & 82.1 & 73.75 & 67.97 & 75.87 & 69.54 \\
640 & 56.4 & 53.41 & 52.08 & 54.09 & 51.13 \\
700 & 53.1 & 49.77 & 48.51 & 50.74 & 48.34 \\
1500 & 26.5 & 24.49 & 28.82 & 26.48 & 28.62 \\
\hline
\end{tabular}

Table 3. OLS regression for preferred tax rates.

\begin{tabular}{ccccc}
\hline Variable & Coefficient & $\begin{array}{c}\text { Robust standard } \\
\text { error }\end{array}$ & T-statistic & P-value \\
\hline Constant: endowment 125 & 76.765 & 1.869 & 41.07 & 0.000 \\
Endowment 275 & -6.878 & 0.888 & -7.75 & 0.000 \\
Endowment 640 & -25.983 & 1.098 & -23.67 & 0.000 \\
Endowment 700 & -29.320 & 1.423 & -20.60 & 0.000 \\
Endowment 1500 & -51.558 & 1.923 & -26.81 & 0.000 \\
Context: neutral & 2.439 & 1.491 & 1.64 & 0.110 \\
Phase: second half & 1.369 & 0.555 & 2.47 & 0.018 \\
\hline
\end{tabular}

Notes: Errors are clustered by group. 
tax rates implemented in the two contexts of this treatment. Because of this, the sum across endowments, of the probit estimates of the proportion of times that the implemented tax rate comes from an individual with one of the five endowments, will exceed unity. In the health context the number of contributors to the 200 tax rates for that context was 231. For the neutral context the number of contributors was 220. Table 4 presents the regression results and Figure 1 presents the actual distributions of implemented tax rates by endowment of the individual whose submitted tax rate is the implemented tax rate by context and phase.

From Figure 1 it is clear that Theoretical Prediction 2 is not supported by the data because individuals other than the individual with the endowment of L\$640 prefer the tax rate that is implemented. This may be a result of the choice of endowments. The difference between the L\$640 endowment of the median income

Table 4. Probit regression identifying the endowment of individuals whose preferred tax rates are implemented.

\begin{tabular}{|c|c|c|c|c|}
\hline Variable & Coefficient & $\begin{array}{c}\text { Robust standard } \\
\text { error }\end{array}$ & Z-statistic & $\mathrm{P}$-value \\
\hline $\begin{array}{l}\text { Constant: } \\
\text { endowment } 125\end{array}$ & -1.446 & 0.110 & -13.19 & 0.000 \\
\hline Endowment 275 & 0.037 & 0.128 & 0.29 & 0.773 \\
\hline Endowment 640 & 1.541 & 0.148 & 10.40 & 0.000 \\
\hline Endowment 700 & 1.269 & 0.137 & 9.26 & 0.000 \\
\hline Endowment 1500 & -0.060 & 0.136 & -0.44 & 0.657 \\
\hline Context: neutral & -0.068 & 0.041 & -1.67 & 0.095 \\
\hline Phase: second half & -0.033 & 0.029 & -1.15 & 0.251 \\
\hline
\end{tabular}

Notes: Errors are clustered by group.

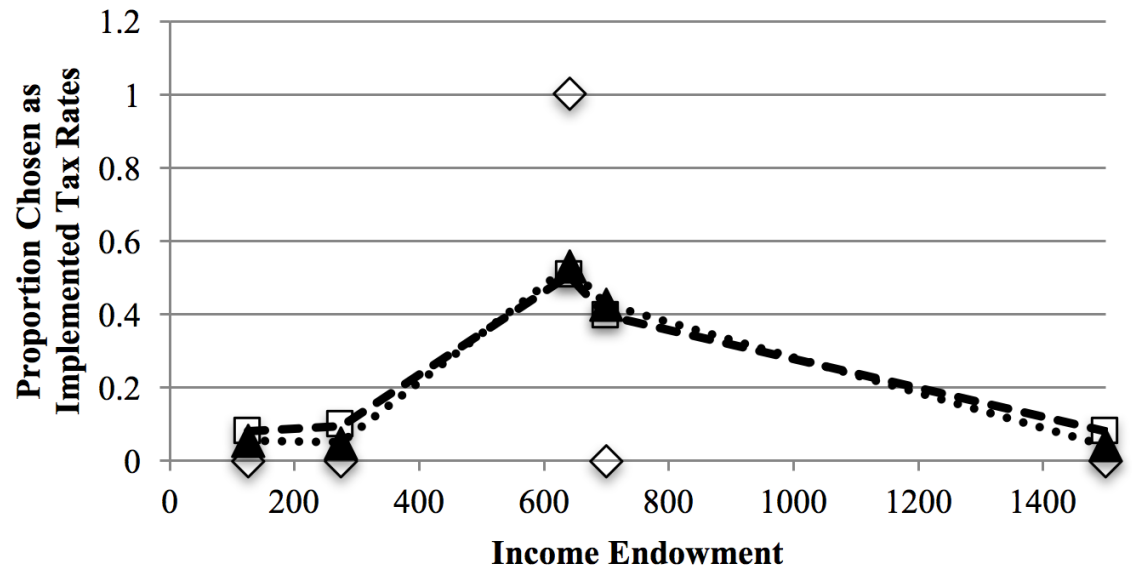

\section{$\diamond$ Predicted $-\square-$ Health $\cdots * \cdot$ Neutral}

Figure 1. Predicted and actual proportions of implemented tax rates by endowment of individuals whose preferred tax rates emerged as the implemented tax rates. 
individual and the individual with the next highest endowment of L\$700 is less than 10 percent of the median income. For each of the other "steps" in endowments, the increases are far larger. The moves to L $\$ 275$ from $\mathrm{L} \$ 125$, to $\mathrm{L} \$ 640$ from $\mathrm{L} \$ 275$ and to $\mathrm{L} \$ 1500$ from $\mathrm{L} \$ 700$ are $120 \%, 133 \%$ and $114 \%$. These are all very different from a $9 \%$ increase. Also, the predicted tax rates for individuals with endowments of $\mathrm{L} \$ 125, \mathrm{~L} \$ 275, \mathrm{~L} \$ 640, \mathrm{~L} \$ 700$ and $\mathrm{L} \$ 1500$ are $93.7 \%, 82.1 \%$, $56.4 \%, 53.1 \%$ and $26.5 \%$. Except for the change from L\$640 to L\$700 of 3 percentage points, the predicted drops in preferred tax rates as endowment falls exceeds 10 percentage points. From Figure 1 it is also clear that the preferred rates of the individuals with endowments of 640 and 700 are generally the implemented tax rates. The preferred tax rate of one of these two individuals is implemented in $87.75 \%$ of the 400 decisions rounds in which a tax rate was implemented. ${ }^{7}$ While the data do not support Theoretical Prediction 2, there is support for a weaker version of Prediction 2 in which there is a large concentration of choices of the implemented tax rate associated with individuals with endowments very close to L $\$ 640$.

The probit regression results support the conclusion that there is no phase effect associated with the determination of the implemented tax rate $(p=0.251)$ and that there is no context effect $(\mathrm{p}=0.095)$. Individuals with endowments of L\$125 are not expected to have their preferred tax rates implemented, but this happens about $8 \%$ of the time. Similarly, individuals with endowments of L\$275 and $\mathrm{L} \$ 1500$ are not expected to have their preferred tax rates implemented but their preferred tax rates are implemented about as often as those of the individuals with endowments of L $\$ 125$. These account for a small but statistically significant number of times, and so while our results show general support for the median voter model, we cannot conclude for our environment that the median voter mechanism consistently implements tax rates preferred by only the voter with the median income endowment. With respect to a context effect, there is no evidence that context affects the likelihood that the implemented tax rate is the preferred tax rate of the participant with the median income endowment.

Figure 2 presents the predicted implemented tax rate and the actual mean implemented tax rates by period for the neutral and health contexts. Each point in Figure 2 is the mean of the implemented tax rates from each of 20 groups for each context. We have 400 observations of implemented tax rates over 10 decision rounds from 40 groups of 5 participants. We analyze these data using an

\footnotetext{
${ }^{7}$ In the periods for which there was more than one individual whose preferred tax rate was the implemented tax rate there were 20 periods in which both the preferred tax rates of individuals with endowments of L $\$ 640$ and L $\$ 700$ were implemented. These occurred 11 times in the health context and 9 times in the neutral context. In the health context the preferred tax rates of the individuals with endowments of $\mathrm{L} \$ 640$ and $\mathrm{L} \$ 700$ were implemented 180 times. In the neutral context this number was 191 times. Because of the times that the preferred tax rates from individuals with both of these endowments were selected, we have to reduce the 180 and 191 numbers by 11 and 9 respectively to obtain the number of times that either $\mathrm{L} \$ 640$ or $\mathrm{L} \$ 700$ was associated with the implemented tax rates. Accordingly, the proportion of times that the individual with the median endowment preferred the implemented tax rate was $84.5 \%(169 / 200)$ for the health context and $91 \%(182 / 200)$ for the neutral context.
} 


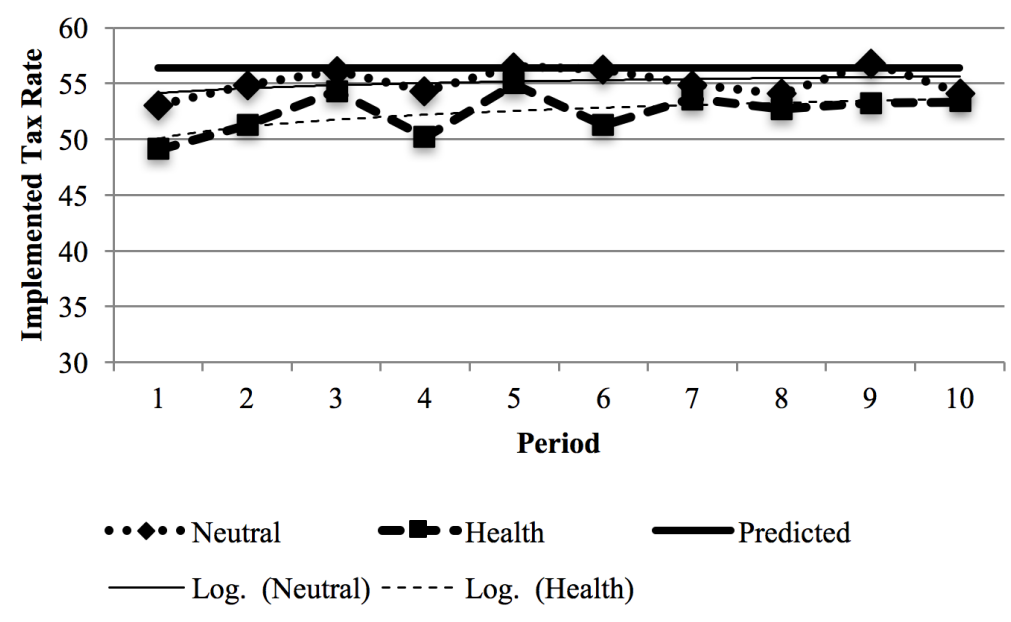

Figure 2. Predicted and actual mean implemented tax rates by period and context.

OLS regression clustered on group. The dependent variables are the context (health or neutral) and the phase (the first five periods or the second five periods). The regression results are presented in Table 5.

The data indicate that implemented tax rates are greater in the neutral context than in the health context and that there is a small increase in the implemented tax rates for both contexts between the first and second phases (see the logarithmic trend lines in Figure 2). However, the regression results indicate that these differences are not statistically significant.

Table 6 presents the predicted and mean actual implemented tax rates, the predicted and mean actual total public provisions of good $h$ and the predicted and mean actual total system payoffs by neutral and health contexts. The data presented in Table 6 are from the last 5-period phase of the health and neutral context treatments. To obtain these values we compute the mean value of each variable for each group over the second phase of the public-only treatment. We then calculate the mean of the 20 group means by context. We have selected this phase for the presentation of results for implemented tax rates, for consumption and for system payoffs because the data indicate slightly higher preferred tax rates and implemented tax rates in the latter periods of the treatment. We interpret this as an effect associated with learning about the environment and is essentially an outcome of the repeated game.

The only variable collected directly from the participants in the laboratory sessions is the preferred tax rate. The median of the preferred tax rates submitted by all participants in the group is chosen as the implemented tax rate for the period. It is the implemented tax rate that determines the public provision of good $h$ consumed by each participant in a group and the amount of good $c$ that is purchased privately. Because the environment does not permit participants to save for future consumption, whatever portion of each participant's endowment not taken by the proportional tax selected by the median voter to provide good $h$ is automatically directed towards the individual's private purchase of good $c$. 
Table 5. OLS regression for implemented tax rates.

\begin{tabular}{ccccc}
\hline Variable & Coefficient & $\begin{array}{c}\text { Robust standard } \\
\text { error }\end{array}$ & T-statistic & P-value \\
\hline $\begin{array}{c}\text { Constant: health } \\
\text { context }\end{array}$ & 52.04 & 1.4703 & 35.39 & 0.000 \\
Context: neutral & 2.73 & 1.6655 & 1.64 & 0.109 \\
Phase: second half & 0.68 & 0.6941 & 0.98 & 0.333 \\
\hline
\end{tabular}

Notes: Errors are clustered by group.

Table 6. Mean per period implemented tax rate, total public provision and aggregate payoffs.

\begin{tabular}{|c|c|c|c|c|c|}
\hline & \multirow{2}{*}{ Predicted } & \multirow{2}{*}{$\begin{array}{c}\text { Neutral } \\
\text { context } \\
\text { (St. Dev.) }\end{array}$} & \multirow{2}{*}{$\begin{array}{l}\text { Health } \\
\text { context } \\
\text { (st. Dev.) }\end{array}$} & \multicolumn{2}{|c|}{$\begin{array}{c}\text { Test of difference across } \\
\text { contexts }\end{array}$} \\
\hline & & & & $\begin{array}{l}\text { P-value } \\
\text { (t-test) }\end{array}$ & $\begin{array}{c}\text { P-value } \\
\text { (MWU-test) }\end{array}$ \\
\hline $\begin{array}{l}\text { Implemented tax } \\
\text { rate }\end{array}$ & 56.4 & $\begin{array}{l}55.24 \\
(3.18) \\
{[0.12]}\end{array}$ & $\begin{array}{l}52.92 \\
(6.40) \\
{[0.03]}\end{array}$ & 0.15 & 0.22 \\
\hline $\begin{array}{l}\text { Total public } \\
\text { consumption }\end{array}$ & 1827 & $\begin{array}{c}1789.78 \\
(102.94) \\
{[0.12]}\end{array}$ & $\begin{array}{c}1714.61 \\
(207.44) \\
{[0.03]}\end{array}$ & 0.12 & 0.21 \\
\hline $\begin{array}{l}\text { Aggregate } \\
\text { payoffs }\end{array}$ & 6550 & $\begin{array}{c}6535.30 \\
(17.46) \\
{[0.00]}\end{array}$ & $\begin{array}{c}6520.05 \\
(69.22) \\
{[0.07]}\end{array}$ & 0.35 & 1.00 \\
\hline Observations & & 20 & 20 & & \\
\hline
\end{tabular}

Notes: The observations are the mean implemented tax rates, mean total public provision and mean aggregate payoffs over periods 6 through 10 for each group. The values in square brackets are p-values associated with a two-sided test of the null that there is no difference between the predicted and actual implemented tax rate.

Whether there is a context effect on consumption of goods $h$ and $c$ and the total payoffs to participants will be determined by the tax rate that is implemented.

The statistics in Table 6 indicate that the mean implemented tax rate in the neutral context is $55.24 \%$. This is not different from the predicted value ( $\mathrm{p}=$ $0.12)$. In the health context the implemented tax rate is $52.92 \%$. This is different from the predicted value $(\mathrm{p}=0.03)$. However, the difference between the two mean implemented tax rates under each context is only $2.32 \%$. The magnitude of this difference is small and the difference is not statistically significant. We cannot reject the null hypothesis that the means are equal in favor of the alternative that the implemented tax rate in the health context is statistically significantly different from the implemented tax rate in the neutral context (t-test, $\mathrm{p}=0.15$; Mann-Whitney test, $\mathrm{p}=0.22$ ). On this basis, we conclude that our data do not support a context effect.

Given that the difference between the mean implemented tax rates for the two contexts is not economically meaningful and that the system consumption of good $h$ data and implemented tax rate data are perfectly correlated, the test re- 
sult reported above will support the conclusion that there is no significant difference between system consumption in the two contexts. System payoffs for the two contexts are $0.2 \%$ lower with the health context than with the neutral context. This difference for system payoffs is not statistically significant ( $\mathrm{t}$-test, $\mathrm{p}=$ 0.35 ; Mann-Whitney test, $\mathrm{p}=1.00$ ). There is no context effect associated with the implemented tax rates, the consumption of the publicly provided private good or the system payoffs.

\section{Summary and Conclusions}

We present data from controlled laboratory sessions in which individuals report their preferred tax rates for collecting resources to publicly finance the provision of a private good. The tax rate that is implemented is the preferred rate of the median voter. With respect to the theoretical predictions related to the implementation of a median voter mechanism in a laboratory environment, we find that preferred tax rates fall as endowments rise and that the preferred tax rates of voters with endowments at or within $10 \%$ of the median endowment select the median tax rate in nearly $90 \%$ of our 400 observations. This generally provides support for the median voter model.

The conjecture that we may find a different tax rate implemented if the private good which is publicly provided is identified specifically as a health care good is not supported by the data. This is contrary to what might arise if the health context evoked a merit-good effect that leads to higher taxes directed to the public provision of the merit good. Accordingly, we find that context does not affect the public provision of the private good or the total group payoff.

As noted earlier, previous studies have found context effects associated with health versus non-health environments with respect to the influence of professional norms on physician decision-making and the decisions individuals make in a controlled laboratory environment regarding the purchase of private health care insurance that permits "queue jumping" for health care services. These are decision settings different than that we investigate. This difference may account for our different results. It is possible that participants recognized that although we identified the publicly provided private good as health care, they also recognized the redistribution effect of the median voter mechanism used to finance this public provision. Accordingly, any preference individuals may have had for contributing to the provision of a merit good may have been satisfied through their required participation in this financing mechanism.

\section{Acknowledgements}

We received helpful comments from the participants in the 3rd Behavioral and Experimental Economics Workshop held in Essen, Germany and from David Feeny. We also acknowledge funding support from the Canadian Social Sciences and Humanities Research Council (Award \#410-2011-2110); SSHRC had no role in the study design, collection, analysis and interpretation of data, the writing of 
the report or in the decision to submit the article for publication. Stephanie Thomas acknowledges support from the Bernie O'Brien Post-Doctoral Fellowship Trust from which she received the O'Brien Fellowship as an exceptional post-doctoral fellow in health economics and health-technology assessment.

\section{References}

[1] Buckley, N., Cuff, K., Hurley, J., Mestelman, S., Thomas, S. and Cameron, D. (2015) Support for Public Provision of a Private Good with Top-Up and Opt-Out: A Controlled Laboratory Experiment. Journal of Economic Behavior and Organization, 111, 177-196. https://doi.org/10.1016/j.jebo.2014.12.016

[2] Buckley, N., Cuff, K., Hurley, J., Mestelman, S., Thomas, S. and Cameron, D. (2016) Should I Stay or Should I Go? Exit Options within Mixed Systems of Public and Private Health Care Finance. Journal of Economic Behavior and Organization, 131, 62-77. https://doi.org/10.1016/j.jebo.2016.05.013

[3] Loewenstein, G. (1999) Experimental Economics from the Vantage-Point of Behavioural Economics. Economic Journal, 109, F25-F34. https://doi.org/10.1111/1468-0297.00400

[4] Harrison, G.W. and List, J.A. (2004) Field experiments. Journal of Economics Literature, 42, 1009-1055. https://doi.org/10.1257/0022051043004577

[5] Alekseev, A., Charness, G. and Gneezy, U. (2017) Experimental Methods: When and Why Contextual Instructions Are Important. Journal of Economic Behavior and Organization, 134, 48-59. https://doi.org/10.1016/j.jebo.2016.12.005

[6] Hurley, J. (2000) The Normative Economics of Health and Health Care. In: Culyer, A.J. and Newhouse, J.P. Eds., Handbook of Health Economics, North Holland, Amsterdam, 56-118.

[7] Shakespeare, W. (1951) Romeo and Juliet. In: Craig, H., Ed., The Complete Works of Shakespeare, Scott, Foresman and Company, Chicago, 404.

[8] Ahlert, M., Felder, S. and Vogt, B. (2012) Which Patients Do I Treat? An Experimental Study with Economists and Physicians. Health Economics Review, 2-1, 111.

[9] Kesternich, I., Schumacher, H. and Winter, J. (2015) Professional Norms and Physician Behavior: Homo Oeconomicus or Homo Hippocraticus? Journal of Public Economics, 131, 1-11. https://doi.org/10.1016/j.jpubeco.2015.08.009

[10] Buckley, N., Cuff, K., Hurley, J., McLeod, L., Nuscheler, R. and Cameron, D. (2012) Willingness-to-Pay for Parallel Private Health Insurance: Evidence from a Laboratory Experiment. Canadian Journal of Economics, 45, 137-166. https://doi.org/10.1111/j.1540-5982.2011.01690.x

[11] Rosner, B. (2010) Fundamentals of Biostatistics. $7^{\text {th }}$ Edition, Brooks Cole, Salt Lake City, Utah, 303.

[12] Fischbacher, U. (2007) Z-Tree: Zurich Toolbox for Ready-Made Economic Experiments. Experimental Economics, 10, 171-178. https://doi.org/10.1007/s10683-006-9159-4 